\title{
RESEARCH
}

Open Access

\section{Pilot trial on the efficacy and safety of pantethine in children with pantothenate kinase-associated neurodegeneration: a single-arm, open-label study}

\author{
Xuting Chang ${ }^{1}$, Jie Zhang ${ }^{1}$, Yuwu Jiang ${ }^{1}$, Bufan Yao $^{2}$, Jingmin Wang ${ }^{1}$ and Ye Wu ${ }^{1 *}$
}

\begin{abstract}
Objective: This study aimed to explore the efficacy and safety of pantethine in children with pantothenate kinaseassociated neurodegeneration (PKAN).

Methods: A single-arm, open-label study was conducted. All subjects received pantethine during the 24-week period of treatment. The primary endpoints were change of the Unified Parkinson's Disease Rating Scale (UPDRS) IIII and Fahn-Marsden (FM) score from baseline to week 24 after treatment.

Results: Fifteen children with PKAN were enrolled, and all patients completed the study. After 24 weeks of treatment with pantethine at $60 \mathrm{mg} / \mathrm{kg}$ per day, there was no difference in either UPDRS I-III $(\mathrm{t}=0.516, P=0.614)$ or FM score $(\mathrm{t}=0.353, P=0.729)$ between the baseline and W24. Whereas the rates of increase in UPDRS I-III $(Z=$ 2.614, $p=0.009)$ and FM scores $(Z=2.643, p=0.008)$ were slowed. Four patients $(26.7 \%)$ were evaluated as "slightly improved" by doctors through blinded video assessment. Patients with lower baseline UPDRS I-III or FM scores were more likely to be improved. The quality of life of family members improved after pantethine treatment, evaluated by PedsQL TM 2.0 FIM scores, whereas the quality of life of the patients was unchanged at W24, evaluated by PedsQL TM 4.0 and PedsQL TM 3.0 NMM. Serum level of CoA was comparable between baseline and W24. There was no drug related adverse event during the study.

Conclusions: Pantethine could not significantly improve motor function in children with PKAN after 24 weeks treatment, but it may delay the progression of motor dysfunction in our study. Pantethine was well-tolerated at 60 $\mathrm{mg} / \mathrm{kg}$ per day.

Trial registration: Clinical trial registration number at www.chictr.org.cn:ChiCTR1900021076, Registered 27 January2019, the first participant was enrolled 30 September 2018, and other 14 participants were enrolled after the trial was registered.
\end{abstract}

Keywords: Pantethine, Pantothenate kinase-associated neurodlegeneration, Efficacy, Safety

* Correspondence: dryewu@263.net

'Department of Pediatrics, Peking University First Hospital, No.1, Xi'an Men Street, West District, Beijing 100034, China

Full list of author information is available at the end of the article

C C The Author(s). 2020 Open Access This article is licensed under a Creative Commons Attribution 4.0 International License, which permits use, sharing, adaptation, distribution and reproduction in any medium or format, as long as you give appropriate credit to the original author(s) and the source, provide a link to the Creative Commons licence, and indicate if changes were made. The images or other third party material in this article are included in the article's Creative Commons licence, unless indicated otherwise in a credit line to the material. If material is not included in the article's Creative Commons licence and your intended use is not permitted by statutory regulation or exceeds the permitted use, you will need to obtain permission directly from the copyright holder. To view a copy of this licence, visit http://creativecommons.org/licenses/by/4.0/. The Creative Commons Public Domain Dedication waiver (http://creativecommons.org/publicdomain/zero/1.0/) applies to the data made available in this article, unless otherwise stated in a credit line to the data. 


\section{Introduction}

Pantothenate kinase-associated neurodegeneration (PKAN, OMIM\#234200, formerly known as Hallervorden-Spatz syndrome), an autosomal recessive disease caused by mutations in the PANK2 [1], is classified into two subtypes, namely, classic and atypical phenotype [2]. Approximately two-thirds of patients are classic phenotype, which is usually characterized by dystonia before 10 years of age and loss of ambulation 10-15 years after the disease onse $\mathrm{t}[3]$. The mutations in PANK2 result in decreased activity of pantothenic acid kinase 2 , which is essential for the biosynthesis of coenzyme A (CoA) using pantothenic acid, thereby leading to the reduction of CoA and iron accumulation in specific brain regions [4]. The estimated prevalence is $1-2 / 1,000,000$ [5]. Therapies tried in patients with PKAN included deep brain stimulation (DBS), deferiprone and fosmetpantotenate (RE-024). Currently there is no promising diseasemodifying therapy for PKAN.

Pantethine is a marketed drug used to treat hyperlipidemia. Studies on a PANK2 knockout Drosophila model [6] and a PANK2 knockout mouse model [7] showed that pantethine could aid mitochondrial dysfunction, increase CoA levels in tissues, and rescue the neuromuscular phenotypes. In this study, we aimed to explore the efficacy and safety of the re-purposed drug treatment of pantethine in children with PKAN.

\section{Methods}

\section{Study design}

A single-arm, open-label study was conducted. All subjects received pantethine during the 24-week period of treatment. This study was approved by the Ethics Committee of Peking University First Hospital and registered at the Chinese Clinical Trial Registry (ChiCTR1900021 076). All the parents or legal guardians of children signed the written informed consent forms before any procedure was done.

\section{Participants}

Patients who met all the following criteria were enrolled: (1) aged 3-16 years who showed progressive dystonia; (2) "eye-of-the-tiger" sign in brain magnetic resonance imaging; (3) pathogenic or likely pathogenic variants identified in PANK2. Patients were excluded if they met any of the following criteria: (1) patients who participated in other clinical trials; (2) with severe liver damage (alanine aminotransferase or aspartate aminotransferase $>3$ times the upper limit of normal value);(3) severe renal damage with glomerular filtration rate $<60 \mathrm{ml} / \mathrm{min}$; (4) with cardiovascular system diseases, including cardiac dysfunction or arrhythmia; (5) abnormalities in blood system (hemoglobin $<60 \mathrm{~g} / \mathrm{L}$, platelet $<50 \times 10^{9} / \mathrm{L}$, neutrophil $<1.0 \times 10^{9} / \mathrm{L}$ ); and (6) patients who underwent DBS in the past 6 months.

\section{Procedure}

The study lasted for 24 weeks. Patients received pantethine through oral administration (capsules, $450 \mathrm{mg}$ per serving, Jarrow Formulas, USA). The dose started at $20 \mathrm{mg} / \mathrm{kg}$ per day, gradually increased to $60 \mathrm{mg} / \mathrm{kg}$ per day within 4 weeks and maintained at $60 \mathrm{mg} / \mathrm{kg}$ per day (divided into two dosage) until the end of the study. During the study, the dosage of other drugs taken by patients at baseline remained unchanged. Patients were contacted weekly by phone to find out if there were any drug related adverse events in the first 5 weeks and were visited at week 12 (W12) and 24 (W24).

The Unified Parkinson's Disease Rating Scale I-III (UPDRS I-III) and Fahn-Marsden Scale (FM) at W-24 (24 weeks before treatment) were retrospectively assessed at baseline. At baseline(W0), UPDRS I-III and FM scores, Activities of daily living (ADL) and Pediatric Quality of Life Inventory (PedsQL) were scaled, motion videos were recorded, and serum CoA levels were measured. At W12 and W24, the UPDRS I-III and FM scores were re-scaled. ADL, PedsQL, parental clinical impression evaluation and blinded video rating were scaled at W24 (Fig. 1).

\section{Assessments of the efficacy and safety}

Assessments of efficacy were conducted using the following measures: (1) UPDRS I-III was used to assess motor symptoms, including mental behavior, daily activity, and motor sections by generating individual scores and a total score (0-124); (2) FM scale was used to measure the severity of dystonia in nine body regions (eyes, mouth, neck, trunk, swallowing, speech, and each upper and lower extremities) by generating individual scores and a total score (0-120); (3) ADL scale was used to measure the patients' ability of daily living, the higher the score, the better the ability of self-care; (4) PedsQL scale was used to measure quality of life, which includes PedsQL4.0 (Generic Core Scales), PedsQL3.0 (Neuromuscular Module), and PedsQL2.0 (Family Impact Module). The first two were used to assess patients' quality of life. PedsQL2.0 was used to evaluate the quality of life of the families; (5) Parental clinical impression scale, which is a subjective instrument consists of a single question, was used to ask parents to rate their children's condition on a scale from 1 (markedly better) to 5 (markedly worse) compared with how they felt at the baseline; (6) Blinded video rating was independently performed by two pediatric neurologists. Conflicts in opinions were resolved by consulting another neurologist to make a decision. Patients' condition at W24 was rated on a scale from 1 (markedly better) to 5 (markedly 


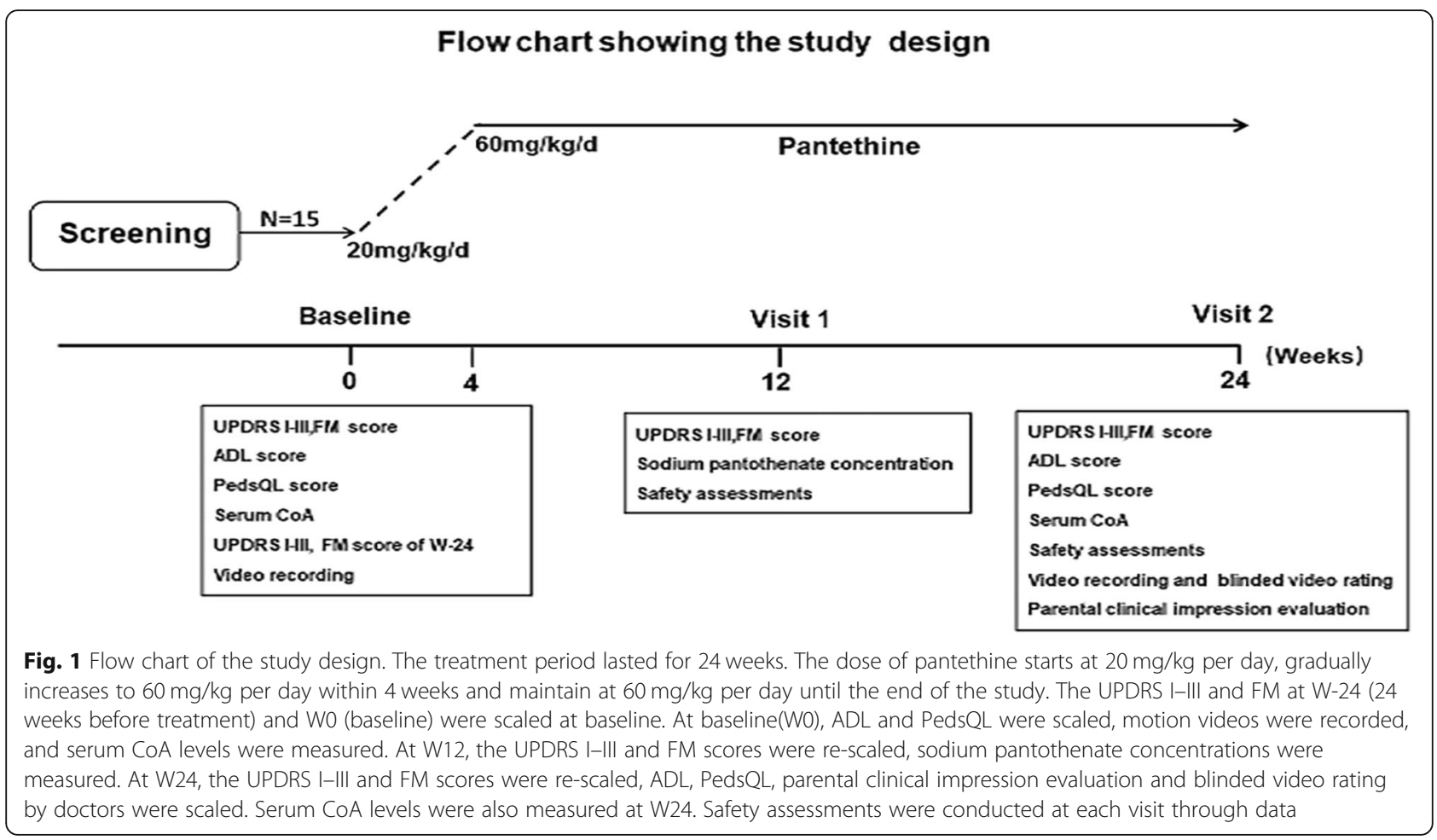

worse) compared with how they felt at baseline through watching the videos (the actions included opening and closing eyes, opening and closing mouth, turning head, eye movements, tapping the index finger with the thumb, stretching and bending arms, placing both arms flexed at the elbow in front of the chest, stamping the foot, finger-nose test, turning body, walking, eating something, writing, and speaking).

Safety assessments were conducted at each visit through data collection of adverse events and clinical laboratory tests including liver function, renal function, and complete blood count.

The primary endpoints were the change of UPDRS IIII and FM scores from baseline to W24 after pantethine treatment. The secondary endpoints were changes in ADL score, PedsQL score, parental clinical impression scale, as well as blinded video rating from baseline to week 24. The increase rates of UPDRS I-III and FM scores 24 week after and before pantethine treatment were also compared.

\section{Measurement of serum CoA}

Blood was extracted at baseline and W24. The serum was immediately centrifuged $(4000 \mathrm{rpm} / \mathrm{min}, 10 \mathrm{~min}$ ) and stored at $-20^{\circ} \mathrm{C}$ until $\mathrm{CoA}$ was measured. Serum CoA was measured using a colorimetric-based kit (Abcam, ab102504) in accordance with the manufacturer's instructions. A CoA standard curve was generated on the basis of optical density and serial dilution of
CoA standard. CoA levels in test samples were calculated using a calibration curve.

\section{Measurement of sodium pantothenate}

Blood was extracted two and five hours after taking pantethine at W12. Sodium pantothenate concentrations were determined by high-performance liquid chromatography coupled with mass spectrometry approach (LC-MS/MS), with ceftiofur as an internal standard. Negative electrospray ionization tandem mass spectrometry with multiple reaction monitoring mode was choose for the detection. Protein precipitation was applied with acetonitrile in the extraction process. The calibration curve was linear over the range of 0.05 to $50 \mu \mathrm{g} / \mathrm{mL}$. The lower limit of quantification (LLOQ) was $0.05 \mu \mathrm{g} / \mathrm{mL}$. The accuracy of low, middle and high concentration controls was $101.9,114.1$ and $114.2 \%$, respectively.

\section{Statistical analysis}

Descriptive statistics were used to summarize the collected data. Categorical variables were summarized on the basis of frequencies and percentages. Continuous variables were summarized on the basis of mean, median, standard deviations, and minimum and maximum values. The change of UPDRS I-III, FM, ADL, and PedsQL scores from baseline to week 24 were compared through paired $t$ test. The increase rate of UPDRS I-III and FM scores before and after treatment were compared using the Wilcoxon rank sum test. The correlation 
between blinded video rating and initial UPDRS I-III/ FM scores at baseline was tested through one-way ANOVA. Spearman's correlation was used to compare the correlation between sodium pantothenate concentrations and change of UPDRS I-III/FM scores. The correlation between parental clinical impression scale/ blinded video rating by doctors and the change of UPDRS I-III/ FM scores during treatment of pantethine was tested through Kendall's tau-b correlation coefficient. All statistical analyses were conducted on SPSS (version 20.0). $P<0.05$ was considered statistically significant.

\section{Results}

\section{Clinical characteristics of patients}

Fifteen children composed of seven males and eight females were enrolled, who were referred from eight hospitals in mainland China, and no patient withdrawal during the 24-week study. The median age at onset was 3.0(1.0-8.0) years. The median age and disease duration at baseline were $10.0(3.5-13.6)$ and $5.3(0.8-12.1)$ years, respectively. All patients enrolled were classic PKAN. For the initial symptom, ten patients (10/15, 66.7\%) showed dystonia in lower limbs, three patients $(3 / 15$, $20.0 \%)$ showed dystonia in upper limbs, two $(2 / 15$, 13.3\%) presented with developmental delay. At the baseline, five patients $(5 / 15,33.3 \%)$ lost the ability of independent ambulance. All patients showed "eye-of-tiger sign" in the brain MRI. The baseline medications taken by the patients included trihexyphenidyl hydrochloride, baclofen, levodopa, clonazepam, clozapine and mantadine (Table 1).

\section{Primary endpoints of efficacy}

To determine whether pantethine treatment could improve the motor function, we compared the UPDRS I-III scores (the assessment of mental behavior, daily activity, and motor function) and FM scores between the W24 and W0 in these patients. There was no significant

Table 1 Clinical and genetic characteristics of the patients

\begin{tabular}{|c|c|c|c|c|c|c|c|c|}
\hline \multirow{2}{*}{$\begin{array}{l}\text { Patient } \\
\text { ID }\end{array}$} & \multirow[t]{2}{*}{ Sex } & \multirow{2}{*}{$\begin{array}{l}\text { Age at } \\
\text { enrollment } \\
\text { (years) }\end{array}$} & \multirow{2}{*}{$\begin{array}{l}\text { Age at } \\
\text { onset } \\
\text { (years) }\end{array}$} & \multirow{2}{*}{$\begin{array}{l}\text { Symptoms } \\
\text { at W-24 }\end{array}$} & \multirow{2}{*}{$\begin{array}{l}\text { Symptoms } \\
\text { at W0 }\end{array}$} & \multirow[t]{2}{*}{ Baseline medication } & \multicolumn{2}{|c|}{ Mutation in PANK2 } \\
\hline & & & & & & & $\begin{array}{l}\text { Change of } \\
\text { nucleotide }\end{array}$ & $\begin{array}{l}\text { Change of } \\
\text { amino acid }\end{array}$ \\
\hline 01 & M & 10.0 & 8.0 & DUL,DLL & DUL,DLL & Levodopa, Baclofen & $\begin{array}{l}\text { c. } 970 \mathrm{G}>\mathrm{T} / \\
\mathrm{c.} .970 \mathrm{G}>\mathrm{T}\end{array}$ & $\begin{array}{l}\text { p.D324Y/ } \\
\text { p.D324Y }\end{array}$ \\
\hline 02 & $\mathrm{~F}$ & 12.6 & 1.5 & DUL,DLL, BS & DUL,DLL, BS & / & c.790C > T/- & p.R264W/ - \\
\hline 03 & M & 11.8 & 1.5 & DUL,DLL, BS & $\begin{array}{l}\text { DUL,DLL, } \\
\text { BS, LOA }\end{array}$ & Trihexyphenidyl hydrochloride & $\begin{array}{l}\text { C. } 1355 \mathrm{~A}>\mathrm{G} / \\
\mathrm{C.} 1555 \mathrm{~T}>\mathrm{C}\end{array}$ & $\begin{array}{l}\text { p.D452G/ } \\
\text { p.F519L }\end{array}$ \\
\hline 04 & $\mathrm{~F}$ & 7.9 & 7.1 & DUL,DLL & DUL,DLL & Levodopa, Baclofen & $\begin{array}{l}\text { c. } 856 \mathrm{C}>\mathrm{T} / \\
\text { c. } 1502 \mathrm{~T}>\mathrm{A}\end{array}$ & $\begin{array}{l}\text { p.R286C/ } \\
\text { p.1501N }\end{array}$ \\
\hline 05 & $\mathrm{~F}$ & 8.9 & 4.0 & DUL,DLL, BS & DUL,DLL, BS & / & $\begin{array}{l}\text { c.1324G }>\mathrm{T} / \\
\text { c.1324G }>\mathrm{T}\end{array}$ & $\begin{array}{l}\text { p.D442Y/ } \\
\text { p.D442Y }\end{array}$ \\
\hline 06 & M & 9.0 & 2.0 & $\begin{array}{l}\text { DUL,DLL, } \\
\text { BS, LOA }\end{array}$ & $\begin{array}{l}\text { DUL,DLL, } \\
\text { BS, LOA }\end{array}$ & $\begin{array}{l}\text { Baclofen, Clonazepam, Amantadine, Clozapine } \\
\text { Trihexyphenidyl hydrochloride }\end{array}$ & $\begin{array}{l}\text { C. } 650 A>G / \\
\text { c. } 1341 \mathrm{~T}>\mathrm{G}\end{array}$ & $\begin{array}{l}\text { p.D217G/ } \\
\text { p.D447E }\end{array}$ \\
\hline 07 & M & 10.2 & 7.8 & DUL,DLL, BS & DUL,DLL, BS & Trihexyphenidyl hydrochloride, Baclofen & $\begin{array}{l}\text { C. } 1502 \mathrm{~T}>\mathrm{A} \\
\text { c. } 833 \mathrm{G}>\mathrm{A}\end{array}$ & $\begin{array}{l}\text { p.1501N/ } \\
\text { p.R278H }\end{array}$ \\
\hline 08 & M & 3.5 & 1.6 & DUL,DLL & DUL,DLL & Trihexyphenidyl hydrochloride, Baclofen & $\begin{array}{l}\text { C. } 1355 A>G / \\
\text { c. } 1355 A>G\end{array}$ & $\begin{array}{l}\text { p.D452G/ } \\
\text { p.D452G }\end{array}$ \\
\hline 09 & $\mathrm{~F}$ & 12.3 & 6.0 & DUL,DLL & DUL,DLL & / & $\begin{array}{l}\text { c. } 981+3 \mathrm{~A}>\mathrm{G} / \\
\text { c. } 970 \mathrm{G}>\mathrm{T}\end{array}$ & Splice/p.D324Y \\
\hline 10 & $\mathrm{~F}$ & 13.6 & 1.5 & $\begin{array}{l}\text { DUL,DLL, } \\
\text { BS, LOA }\end{array}$ & $\begin{array}{l}\text { DUL,DLL, } \\
\text { BS, LOA }\end{array}$ & $\begin{array}{l}\text { Baclofen, Tiapride, Levodopa, Trihexyphenidyl } \\
\text { hydrochloride }\end{array}$ & $\begin{array}{l}\text { c.595C }>T / \\
\text { c. } 1351 C>T\end{array}$ & $\begin{array}{l}\text { P.Q199X/ } \\
\text { p.R451X }\end{array}$ \\
\hline 11 & $\mathrm{~F}$ & 10.3 & 5.0 & DUL,DLL, BS & DUL,DLL, BS & Trihexyphenidyl hydrochloride, Clonazepam & $\begin{array}{l}\text { C. } 1213 \mathrm{~T}>\mathrm{Cl} \\
\text { c.510-522del }\end{array}$ & $\begin{array}{l}\text { p.Y405H/ } \\
\text { p.A170Afs*31 }\end{array}$ \\
\hline 12 & $\mathrm{~F}$ & 8.3 & 2.0 & DUL,DLL, BS & DUL,DLL, BS & $\begin{array}{l}\text { Trihexyphenidyl hydrochloride, Baclofen, } \\
\text { Levodopa }\end{array}$ & $\begin{array}{l}\text { C. } 1355 A>G / \\
\text { c. } 1355 A>G\end{array}$ & $\begin{array}{l}\text { p.D452G/ } \\
\text { p.D452G }\end{array}$ \\
\hline 13 & M & 4.5 & 1.0 & $\begin{array}{l}\text { DUL,DLL, } \\
\text { BS, LOA }\end{array}$ & $\begin{array}{l}\text { DUL,DLL, } \\
\text { BS, LOA }\end{array}$ & Levodopa, Clonazepam & $\begin{array}{l}\text { C. } 1351 C>T / \\
\text { C. } 1355 A>G\end{array}$ & $\begin{array}{l}\text { p.R451X/ } \\
\text { p.D452G }\end{array}$ \\
\hline 14 & M & 5.6 & 2.0 & DUL,DLL, BS & DUL,DLL, BS & / & $\begin{array}{l}\text { c.644- } \\
\text { 645delGAinsAT/ } \\
\text { c.1151C>G }\end{array}$ & $\begin{array}{l}\text { p.D215dellinsD/ } \\
\text { p.P384R }\end{array}$ \\
\hline 15 & $\mathrm{~F}$ & 10.1 & 3.0 & DUL,DLL & $\begin{array}{l}\text { DUL,DLL, } \\
\text { LOA }\end{array}$ & Trihexyphenidyl hydrochloride & $\begin{array}{l}\text { c. } 1082 A>G / \\
\text { c. } 1355 A>G\end{array}$ & $\begin{array}{l}\text { p.Y361C/ } \\
\text { p.D452G }\end{array}$ \\
\hline
\end{tabular}

$M: m a l e, F$ female, $L O A$ loss of independent ambulance, DLL dystonia in lower limbs, DUL dystonia in upper limbs, BS bulbar symptoms,

"-":not identified, " "/": no medication was taken at baseline, the transcript ID is NM_153638 
difference between the baseline (W0) and W24 after the treatment, in either total UPDRS I-III scores or individual score of UPDRS I, II and III (Table 2). Moreover, the FM scores did not change significantly at W24 compared to W0 (Table 3). The results suggested that there was no significant improvement in motor handicap after 24 weeks of pantethine.

\section{Secondary endpoints of efficacy \\ Rate of the increase in UPDRS I-III and FM scores 24 weeks before and after pantethine treatment}

To clarify whether pantethine could slow the progression of motor dysfunction in children with PKAN, we compared the rate of increase in score of UPDRS I-III and FM 24 week before and after the pantethine treatment. The rates of increase in the total score of UPDRS I-III, individual score of UPDRS I-III and FM scores were significantly slowed after the treatment (Table 2, Table 3, Fig. 2). The results indicated that pantethine may slow the progression of motor dysfunction.

\section{Parental clinical impression scale and blinded video rating by doctors at W24}

The subjective clinical impression was scaled by the parents or legal guardians of the fifteen children at W24. "Slightly improved" was rated by three parents $(3 / 15$, $20.0 \%)$, "No change" in three $(3 / 15,20.0 \%)$, "slightly deteriorated" in seven $(7 / 15,46.7 \%)$, and "markedly worse" in two parents $(2 / 15,13.3 \%)$ (Table 4$)$. Parental clinical impression scale was consistent with the change of UPDRS I-III and FM scores during the 24-week treatment. (Kendall's tau-b $=0.601, P=0.005 /$ Kendall's tau$\mathrm{b}=0.508, P=0.017)$.

Pediatricians blindly compared the videos of motor action for each patient at W24 and W0. Four patients (4/ $15,26.7 \%)$ were rated as "slightly improved", three $(3 / 15$, $20.0 \%)$ "unchanged", five $(5 / 15,33.3 \%)$ " slightly worse", and three patients $(3 / 15,20.0 \%)$ were "markedly worse". The blinded video rating by doctors of 12 patients (12/ $15,80.0 \%)$ was consistent with the parental clinical impression scale (Table 4). Blinded video rating by doctors was consistent with the change of UPDRS I-III and FM scores and parental clinical impression scale (Kendall's tau-b $=0.666, P=0.002 / \quad K e n d a l l ' s$ tau-b $=0.587, P=$ $0.005 /$ Kendall's tau-b $=0.876, P<0.001)$. The UPDRS IIII and FM scores of all patients who were assessed as "slightly improved" in blinded video rating declined after pantethine treatment.

Subsequent analysis showed that blinded video rating was significantly associate with the UPDRS I-III ( $\mathrm{F}=$ 8.708, $P=0.003)$ and FM scores $(\mathrm{F}=4.401, P=0.029)$ at the baseline. In patients with lower baseline UPDRS I-III or FM scores, they were more likely to be assessed as "slightly improved", which may indicated that patients with relatively mild motor handicap at baseline were more likely to improve after the treatment.

\section{ADL scale and PedsQL scale at baseline and W24}

There was no difference between the W0 and W24 in ADL scale, which was used to measure the patients' ability of daily living. With regard to the quality of life, there was an increase in PedsQL TM 2.0 FIM scores at W24, suggesting the improvement of the quality of life of the family members. Whereas, the quality of life of the patients remained unchanged, which was evaluated by PedsQL TM4.0 and PedsQL TM 3.0 NMM (Table 4).

\section{Serum CoA}

The serum level of CoA at the baseline and W24 were $26.1(9.3-122.4) \mathrm{nmol} / \mathrm{mL}$ and $14.3(16.5-162.0)$ $\mathrm{nmol} / \mathrm{mL}$, respectively. No significant difference was found before and after 24 weeks of treatment $(\mathrm{Z}=$ 1.014, $P=0.31$ ).

\section{Sodium pantothenate in plasma}

Sodium pantothenate in plasma was measured in 13 subjects. The plasma sodium pantothenate concentrations were $1.56 \pm 0.91 \mu \mathrm{g} / \mathrm{ml}$ and $1.04 \pm 0.34 \mu \mathrm{g} / \mathrm{ml}$ at $2 \mathrm{~h}$ and $5 \mathrm{~h}$ after taking pantethine. There was no significant correlation between the concentration of sodium pantothenate at two hours after taking pantethine and the efficacy, represented as the change of UPDRS I-III or FM score (rs $=0.094, P=0.76 / \mathrm{rs}=0.179, P=0.558)$.

\section{Safety}

Pantethine was well tolerated in all children during the 24-week treatment. Two patients showed mild nausea and poor appetite. Liver and renal function, as well as blood routine remained normal during the study period.

\section{Discussion}

In this pilot study on 15 children with PKAN, we did not find 24 weeks of pantethine could significantly improve the motor function, but we found that it may delay the progression of motor dysfunction. The motor function in four children (26.7\%) had a slight improvement 24 weeks after pantethine treatment, which was consistently with the change of score in UPDRS I-III or FM. We found that patients with lower baseline UPDRS I-III or FM scores were more likely to be assessed as "slightly improved", which may indicate that patients with relatively mild motor handicap at baseline were more likely to improve after the treatment, and it may also be due to fluctuations in their own condition over time. Therefore, further study with longer time and larger sample size is needed.

Appropriate dose of pantethine for PKAN is unknown yet. The recommended dose for adults with hyperlipidemia 


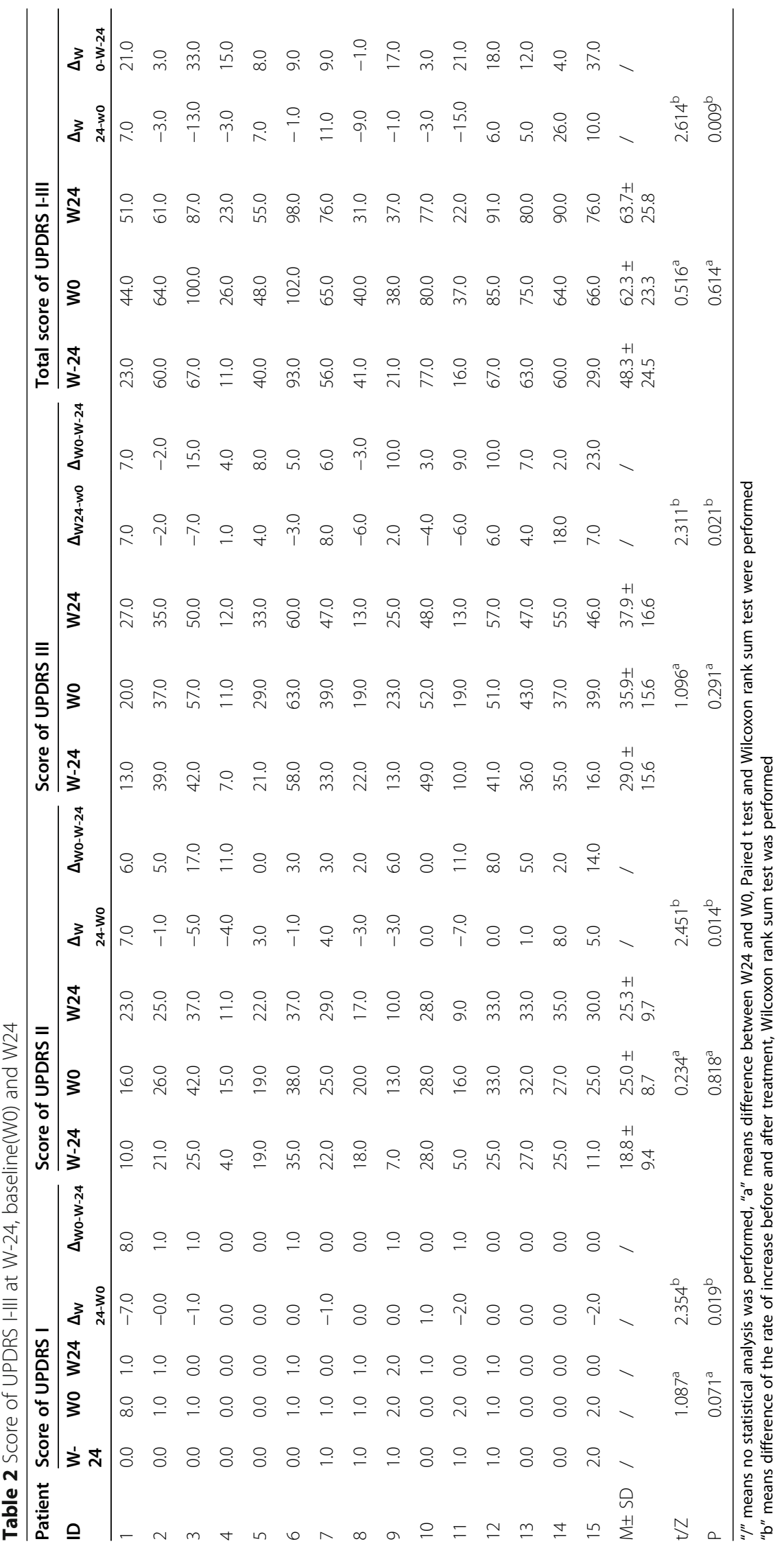


Table 3 FM score at baseline(W0) and W24

\begin{tabular}{llllll}
\hline ID & W-24 & W0 & W24 & $\boldsymbol{\Delta}_{\text {W24-Wo }}$ & $\boldsymbol{\Delta}_{\text {Wo-W-24 }}$ \\
\hline 1 & 24.0 & 44.0 & 42.0 & -2.0 & 20.0 \\
2 & 63.0 & 72.0 & 61.0 & -11.0 & 9.0 \\
3 & 55.0 & 75.0 & 66.0 & -9.0 & 20.0 \\
4 & 8.0 & 12.0 & 9.0 & -3.0 & 4.0 \\
5 & 40.0 & 50.0 & 44.0 & -6.0 & 10.0 \\
6 & 90.0 & 102.0 & 94.0 & -8.0 & 12.0 \\
7 & 51.0 & 71.0 & 75.0 & 4.0 & 20.0 \\
8 & 18.0 & 18.0 & 16.0 & -2.0 & 0.0 \\
9 & 15.0 & 31.0 & 35.0 & 4.0 & 16.0 \\
10 & 65.0 & 60.0 & 61.0 & 1.0 & -5.0 \\
11 & 6.0 & 24.0 & 15.0 & -9.0 & 18.0 \\
12 & 60.0 & 70.0 & 76.5 & 6.5 & 10.0 \\
13 & 46.0 & 49.0 & 56.0 & 7.0 & 3.0 \\
14 & 36.0 & 51.0 & 74.0 & 23.0 & 15.0 \\
15 & 23.0 & 49.0 & 67.0 & 18.0 & 26.0 \\
$\mathbf{M} \pm$ SD & $40.0 \pm 24.3$ & $51.9 \pm 24.3$ & $52.8 \pm 25.3$ & $/$ & $/$ \\
$\mathbf{t} / \mathbf{Z}$ & & $0.353^{\mathrm{a}}$ & & $2.643^{\mathrm{b}}$ & \\
$\mathbf{P}$ & & $0.729^{\mathrm{a}}$ & & $0.008^{\mathrm{b}}$ & \\
\hline
\end{tabular}

"/" means no statistical analysis was performed

"a" means difference between W24 and W0, Paired t test was performed

" $b$ " means difference of the rate of increase before and after treatment,

Wilcoxon rank sum test was performed

is $600 \mathrm{mg}$ per day $(10 \mathrm{mg} / \mathrm{kg}$ per day), which is insufficient for patients with PKAN considering the concentration for working on central nervous system. Previous experience on patients with cystinosis showed the dosage at $70 \mathrm{mg} / \mathrm{kg}$ per day was well tolerated [8]. Therefore, we chose the dosage of $60 \mathrm{mg} / \mathrm{kg}$ per day in the present study. Due to limited number of the patients, we did not try different dosage. We measured the concentration of pantethine and sodium pantothenate in the plasma. We could only detect sodium pantothenate but not pantethine, which is because that pantethine was rapidly hydrolyzed to pantothenic acid and cysteamine [8]. The peak plasma concentration of the sodium pantothenate at $2 \mathrm{~h}$ after taking pantethine was $1.56 \pm 0.91 \mu \mathrm{g} / \mathrm{ml}$. The dosage of $60 \mathrm{mg} / \mathrm{kg}$ per day was well tolerated in all children during the treatment. Higher dosage is worth to be explored in future studies.

To our acknowledge, there is no promising diseasemodifying therapies for PKAN yet. Therapies used in patients included deep brain stimulation (DBS), deferiprone fosmetpantotenate (RE-024), 4'-phosphopantetheine and CoA-Z. A meta-analysis on DBS [9] has shown that it could improve the dystonia movement scores in patients with PKAN one year postoperatively. Dystonia of three out of five patients improved after DBS up to 36 months postoperatively in a case series study [10]. Overall, DBS could initially improve the dystonia movement scores in some patients with PKAN but could not stop the disease progression. Thomas Klopstock et al. [11] conducted a randomized, double-blind, controlled trial to explore the safety and efficacy of deferiprone for PKAN. Seventy-six patients were recruited in the 18-month study. No obvious difference was found in the Barry-Albright Dystonia Scale (BAD) and Patients Global Impression of Improvement scores (PGI-I) between the deferiprone and placebo groups. The progression in patients switching from placebo to deferiprone reduced in the extension study, similar with the effect of pantethine in our trial. Christou et al. [12] conducted a study on a single patient with oral administration of RE-024 (Fosmetpantotenate) for 12 months. The clinical parameters improved in this patient, including UPDRS scale, Barry-Albright Dystonia Scale, and 25 -ft walk test. However, there was no significant difference in primary endpoint between RE-024 groups and placebo groups in phase III clinical trials according to Retrophin's announcement. The clinical trials about CoA-Z is ongoing. PZ-2891 treatment elevated brain
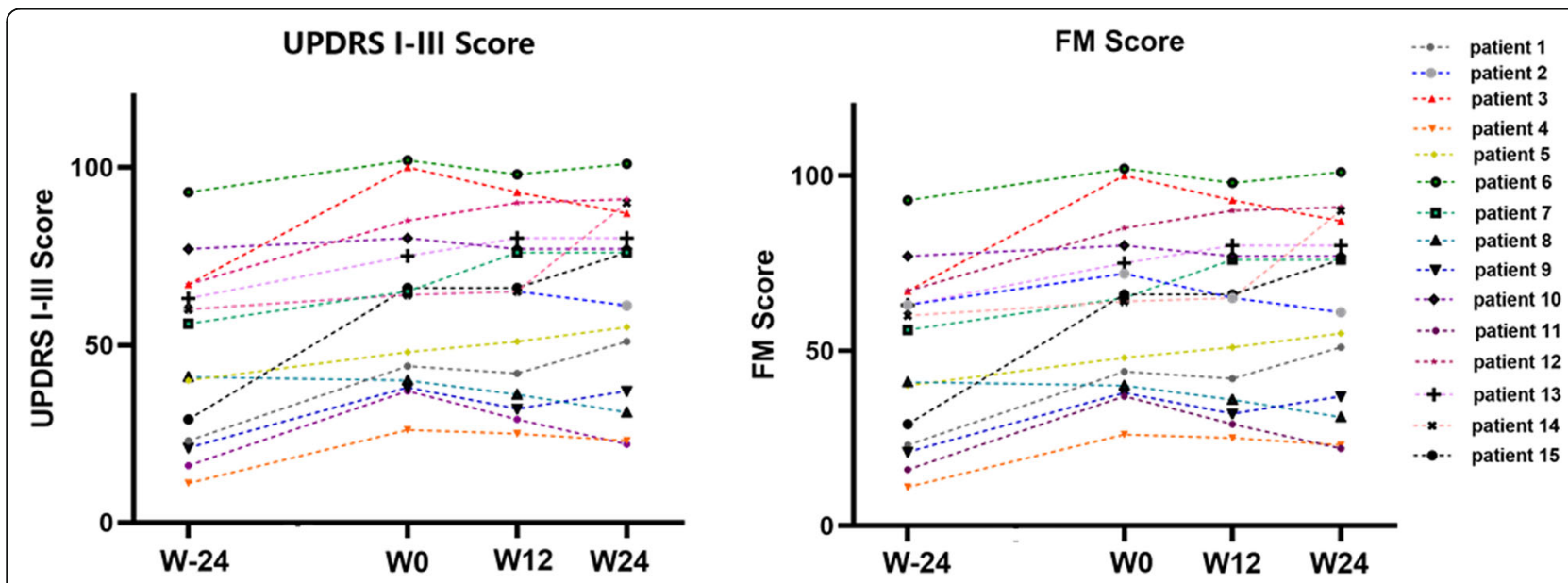

Fig. 2 UPDRS I-III and FM score of 15 patients at W-24, WO, W12 and W 24. Each line in the figure represented an individual 
Table 4 The secondary endpoints at baseline and W24

\begin{tabular}{|c|c|c|c|c|c|c|c|c|c|c|}
\hline \multirow[t]{2}{*}{$\begin{array}{l}\text { Patient } \\
\text { ID }\end{array}$} & \multicolumn{2}{|l|}{ ADL Score } & \multicolumn{2}{|c|}{$\begin{array}{l}\text { PedsQL TM } 4.0 \\
\text { Score }\end{array}$} & \multicolumn{2}{|c|}{$\begin{array}{l}\text { PedsQL TM } 3.0 \text { NMM } \\
\text { Score }\end{array}$} & \multicolumn{2}{|c|}{$\begin{array}{l}\text { PedsQL TM 2.0FIM } \\
\text { Score }\end{array}$} & \multirow{2}{*}{$\begin{array}{l}\text { Parental } \\
\text { Clinical } \\
\text { Impression } \\
\text { Scale }\end{array}$} & \multirow[t]{2}{*}{$\begin{array}{l}\text { Blinded video } \\
\text { rating }\end{array}$} \\
\hline & wo & W24 & wo & W24 & wo & W24 & wo & W24 & & \\
\hline 1 & 75.0 & 65.0 & 61.8 & 23.0 & 60.0 & 62.0 & 50.0 & 58.8 & Slightly worse & Slightly worse \\
\hline 2 & 10.0 & 40.0 & 30.0 & 27.8 & 39.0 & 36.0 & 71.5 & 50.0 & Same & Slightly better \\
\hline 3 & 25.0 & 15.0 & 36.0 & 39.5 & 48.0 & 49.0 & 58.8 & 69.0 & Same & Same \\
\hline 4 & 75.0 & 85.0 & 52.8 & 88.0 & 75.0 & 92.0 & 85.8 & 85.3 & Slightly better & Slightly better \\
\hline 5 & 85.0 & 80.0 & 67.5 & 56.5 & 62.0 & 56.0 & 63.5 & 81.8 & Slightly worse & Slightly worse \\
\hline 6 & 10.0 & 10.0 & 29.0 & 25.0 & 35.0 & 30.0 & 50.0 & 73.8 & Slightly worse & Same \\
\hline 7 & 45.0 & 45.0 & 42.5 & 45.0 & 52.0 & 40.0 & 29.0 & 45.3 & Slightly worse & Markedly worse \\
\hline 8 & 50.0 & 55.0 & 61.3 & 60.0 & / & / & 55.5 & 53.5 & Slightly better & Slightly better \\
\hline 9 & 95.0 & 95.0 & 59.8 & 58.8 & 68.0 & 72.0 & 70.3 & 75.8 & Slightly worse & Slightly worse \\
\hline 10 & 25.0 & 25.0 & 16.0 & 42.5 & 38.0 & 62.0 & 41.3 & 40.0 & Same & Same \\
\hline 11 & 85.0 & 90.0 & 35.0 & 73.9 & 77.0 & 81.0 & 50.0 & 59.5 & Slightly better & Slightly better \\
\hline 12 & 50.0 & 20.0 & 23.8 & 38.3 & 31.0 & 44.0 & 55.5 & 79.8 & Markedly worse & Markedly worse \\
\hline 13 & 35.0 & 30.0 & 65.8 & 35.0 & / & / & 41.3 & 40.0 & Slightly worse & Slightly worse \\
\hline 14 & 50.0 & 40.0 & 35.8 & 22.5 & 40.0 & 45.0 & 58.8 & 60.8 & Slightly worse & Slightly worse \\
\hline 15 & 50.0 & 35.0 & 36.0 & 44.8 & 52.0 & 49.0 & 32.5 & 46.5 & Markedly worse & Markedly worse \\
\hline$M \pm S D$ & $49.3 \pm 28.1$ & $53.0 \pm 25.1$ & $55.2 \pm 18.1$ & $45.3 \pm 19.1$ & $52.1 \pm 15.4$ & $55.2 \pm 18.1$ & $54.2 \pm 15.1$ & $61.3 \pm 15.4$ & / & / \\
\hline t & $1.361^{\mathrm{a}}$ & & $0.332^{a}$ & & $1.142^{\mathrm{a}}$ & & $2.306^{a}$ & & / & / \\
\hline$P$ & $0.195^{a}$ & & $0.745^{a}$ & & $0.276^{a}$ & & $0.037^{a}$ & & / & / \\
\hline
\end{tabular}

"/" means no statistical analysis was performed

" $a$ " means difference between W24 and W0, Paired t test was performed

CoA and improved motor function in a mouse model [13] .4'-phosphopantetheine normalized levels of the CoA, iron, and activities of mitochondrial enzymes in a mice model [14].

Current hypothesis for neurodegeneration of PKAN is that the mutations of $P A N K 2$ result in reduction of $\mathrm{CoA}$ and the iron accumulation in specific brain regions. And previous studies on a PANK2 knockout Drosophila model [6] showed that pantethine could increase CoA levels in tissues, which indicating that CoA may be an indicator to evaluate efficacy of pantethine in PKAN. No significant change in serum CoA level was found in the present study after 24 weeks of treatment, which was consistent with Jackowski et al, [15] indicating that serum CoA is not a suitable biomarker. The PANK2 enzyme is widely expressed in bone marrow, brain and other 25 tissues. It is localized to mitochondria of neurons in human and mouse brain, [16] CoA in mitochondria may need to be detected.

Some limitations were in the present study: (1) This is a single-arm, open-label study. The number of patients was limited. (2) The treatment duration was not long. (3) We did not try different dosage of pantethine in the study. (4) Blood concentration of sodium pantothenate was collected only at $2 \mathrm{~h}$ and $5 \mathrm{~h}$ after taking pantethine. Trough concentration just before taking medicine was not collected. (5) The UPDRS I-III and FM scores at W24 were retrospectively scaled.

\section{Conclusions}

In this study on 15 children with PKAN, we did not find 24 weeks of pantethine could significantly improve motor function, but we found that it may delay the progression of motor dysfunction. Patients tolerated very well to the dosage of $60 \mathrm{mg} / \mathrm{kg}$ per day. Higher dosage in larger patient samples should be studied to determine the therapeutic effects in PKAN.

\section{Abbreviations}

PKAN: Pantothenate kinase-associated neurodegeneration; DBS: Deep brain stimulation; CoA: Coenzyme A; UPDRS: Unified Parkinson's Disease Rating Scale; FM: Fahn-Marsden Scale; ADL: Activities of daily living; PedsQL: Pediatric Quality of Life Inventory; BAD: Barry-Albright Dystonia Scale; PGI-I: Patients Global Impression of Improvement scores

\section{Acknowledgments}

This study was supported by the National Science and Technology Major Project of the Ministry of Science and Technology of China

(2017ZX09304029-006). We appreciate Prof. Bing Zhou from Department of Biological Sciences and Biotechnology Tsinghua University, for the promoting of this study, who is the first author who identified the PANK2 defect in Hallervorden-Spatz syndrome in 2001. The authors appreciate Prof. Wei Zhao and Zixuan Guo from Department of Pharmacy, Shandong Provincial Qianfoshan Hospital, Jinan, for their assistance in the measurement of sodium pantothenate in plasma. We appreciate the support of Meixia Shang from Department of Medical Statistics, Peking University First Hospital for statistical analysis. We appreciate Shuqing Chen and Chaoyang Chen from 
Department of Pharmacy, Peking University First Hospital for the design of the study.

\section{Authors' contributions}

Xuting Chang designed the study and wasresponsible for data collection, data analysis and drafting the initial manuscript. Jie Zhang was responsible for study design and data analysis. Yuwu Jiang and Jingmin Wang were responsible for recruitment of the patients and revising the manuscript critically. Bufan Yao was responsible for measurement of plasma concentration of sodium pantothenate. Ye Wu was responsible for study design, data analysis, recruitment of the patients, revising the manuscript critically and approving the final submission. All authors are responsible for the accuracy of the work. The author(s) read and approved the final manuscript.

\section{Funding}

The study was supported by National Science and Technology Major Project of the Ministry of Science and Technology of China (2017ZX09304029-006).

\section{Availability of data and materials}

The datasets used and/or analyzed during the current study are available from the corresponding author on reasonable request.

\section{Ethics approval and consent to participate}

The study was approved by the Ethics Committee of Peking University First Hospital and all procedures followed were in accordance with the ethical standards of the responsible committee on human experimentation (institutional and national) and with the Helsinki Declaration of 1975, as revised in 2000. All the parents or legal guardians of children signed written informed consent forms.

\section{Consent for publication}

Consent for publication were obtained from all parents or legal guardians.

\section{Competing interests}

The authors declare that they have no competing interests.

\section{Author details}

'Department of Pediatrics, Peking University First Hospital, No.1, Xi'an Men Street, West District, Beijing 100034, China. ${ }^{2}$ Department of Clinical Pharmacy, School of Pharmaceutical Sciences, Shandong University, Jinan, China.

Received: 20 April 2020 Accepted: 7 September 2020

Published online: 14 September 2020

\section{References}

1. Zhou B, Westaway SK, Levinson B, Johnson MA, Gitschier J, Hayflick SJ. A novel pantothenate kinase gene (PANK2) is defective in Hallervorden-Spatz syndrome. Nat Genet. 2001;28(4):345-9.

2. Razmeh S, Habibi AH, Orooji M, Alizadeh E, Moradiankokhdan K, Razmeh B. Pantothenate kinase-associated neurodegeneration: clinical aspects, diagnosis and treatments. Neurol Int. 2018;10(1):7516.

3. Hayflick SJ, Westaway SK, Levinson B, Zhou B, Johnson MA, Ching KH, Gitschier J. Genetic, clinical, and radiographic delineation of HallervordenSpatz syndrome. New Engl J Med. 2003;348(1):33-40.

4. Kurian MA, Hayflick SJ. Pantothenate kinase-associated neurodegeneration (PKAN) and PLA2G6-associated neurodegeneration (PLAN): review of two major neurodegeneration with brain iron accumulation (NBIA) phenotypes. Int Rev Neurobiol. 2013:110:49-71.

5. Brezavar D, Bonnen PE. Incidence of PKAN determined by bioinformatic and population-based analysis of 140,000 humans. Mol Gen Genomics. 2019; 128(4):463-9.

6. Rana A, Seinen E, Siudeja K, Muntendam R, Srinivasan B, Van Der Want JJ, Hayflick S, Reijngoud D-J, Kayser O, Sibon OC. Pantethine rescues a Drosophila model for pantothenate kinase-associated neurodegeneration. Proc Natl Acad Sci U S A. 2010;107(15):6988-93.

7. Brunetti D, Dusi S, Giordano C, Lamperti C, Morbin M, Fugnanesi V, Marchet S, Fagiolari G, Sibon O, Moggio M, D'amati G, Tiranti V. Pantethine treatment is effective in recovering the disease phenotype induced by ketogenic diet in a pantothenate kinase-associated neurodegeneration mouse model. Brain. 2014;137(Pt 1):57-68.
8. Wittwer CT, Gahl WA, Butler JD, Zatz M, Thoene JG. Metabolism of pantethine in cystinosis. J Clin Invest. 1985;76(4):1665-72.

9. De Vloo P, Lee DJ, Dallapiazza RF, Rohani M, Fasano A, Munhoz RP, Ibrahim GM, Hodaie M, Lozano AM, Kalia SK. Deep brain stimulation for pantothenate kinase-associated neurodegeneration: a meta-analysis. Mov Disord. 2019;34(2):264-73.

10. Svetel M, Tomic A, Dragasevic N, Petrovic I, Kresojevic N, Jech R, Urgosik D, Banjac I, Vitkovic J, Novakovic I. Clinical course of patients with pantothenate kinase-associated neurodegeneration (PKAN) before and after DBS surgery. J Neurol. 2019;266(12):2962-9.

11. Klopstock T, Tricta F, Neumayr L, Karin I, Zorzi G, Fradette C, Kmiec T, Buchner B, Steele HE, Horvath R. Safety and efficacy of deferiprone for pantothenate kinase-associated neurodegeneration: a randomised, doubleblind, controlled trial and an open-label extension study. Lancet Neurol. 2019:18(7):631-42

12. Christou YP, Tanteles GA, Kkolou E, Ormiston A, Konstantopoulos K, Beconi M, Marshall RD, Plotkin H, Kleopa KA. Open-label Fosmetpantotenate, a Phosphopantothenate replacement therapy in a single patient with atypical PKAN. Case Rep Neurol Med. 2017;2017:3247034.

13. Sharma LK, Subramanian C, Yun M, Frank MW, White SW, Rock CO, Lee RE, Jackowski S. A therapeutic approach to pantothenate kinase associated neurodegeneration. Nat Commun. 2018;9(1):4399.

14. Jeong SY, Hogarth P, Placzek A, Gregory AM, Fox R, Zhen D, Hamada J, Van Der Zwaag M, Lambrechts R, Jin H, Nilsen A, Cobb J, Pham T, Gray N, Ralle M, Duffy M, Schwanemann L, Rai P, Freed A, Wakeman K, Woltjer RL, Sibon OC, Hayflick SJ. 4'-Phosphopantetheine corrects CoA, iron, and dopamine metabolic defects in mammalian models of PKAN. EMBO Mol Med. 2019; 11(12):e10489.

15. Jackowski S. Proposed therapies for Pantothenate-kinase-associated Neurodegeneration. J Exp Neurosci. 2019;13:117906951985111.

16. Brunetti D, Dusi S, Morbin M, Uggetti A, Moda F, D'amato I, Giordano C, D'amati G, Cozzi A, Levi S. Pantothenate kinase-associated neurodegeneration: altered mitochondria membrane potential and defective respiration in Pank2 knock-out mouse model. Hum Mol Genet. 2012;21(24):5294-305.

\section{Publisher's Note}

Springer Nature remains neutral with regard to jurisdictional claims in published maps and institutional affiliations.

Ready to submit your research? Choose BMC and benefit from:

- fast, convenient online submission

- thorough peer review by experienced researchers in your field

- rapid publication on acceptance

- support for research data, including large and complex data types

- gold Open Access which fosters wider collaboration and increased citations

- maximum visibility for your research: over $100 \mathrm{M}$ website views per year

At BMC, research is always in progress.

Learn more biomedcentral.com/submissions 